\title{
Inclusão produtiva, pecuária familiar e situação das mulheres rurais do Programa Brasil Sem Miséria em um município do RS - contexto de uma realidade conhecida pouco
}

\author{
MARTA JULIA MARQUES LOPES \\ Universidade Federal do Rio Grande do Sul \\ TATIELLE BELEM LANGBECKER \\ Universidade Federal de Santa Maria
}

\begin{abstract}
Resumo
O objetivo principal deste artigo é descrever e analisar características sociodemográficas de mulheres rurais atuantes na pecuária familiar, inseridas no Plano Brasil sem Miséria, em Encruzilhada do Sul. Essa modalidade de trabalho é culturalmente definida como masculina, assim, questiona-se como as mulheres nela se inserem. No Rio Grande do Sul, a Metade Sul tem na pecuária de corte sua atividade produtiva principal, o que alude a uma suposta homogeneidade produtiva. Essa condição desafia e impulsiona pesquisas que demonstrem a multiplicidade das vivências das famílias rurais pecuaristas. Desta forma, a motivação deste artigo também fundamenta-se na discussão de problemáticas pouco debatidas sobre a pecuária familiar, como a divisão sexual do trabalho e a participação feminina na atividade. Assim, constatou-se a presença de mulheres na pecuária familiar e sua inserção no Programa Brasil Sem Miséria. As informações analisadas mostram que $92,31 \%$ da titularidade no Programa é de mulheres, 6,59\% de homens e 1,10\% de ambos. Essa realidade remete à ideia de protagonismo feminino na ação, entretanto há que se considerar outras questões que contribuem para outras possibilidades explicativas dessa condição. A trajetória e a divisão sexual do trabalho, "destinando" as mulheres aos trabalhos mais precários, é possível que seja uma potencial resposta. Dessa forma, o reconhecimento do trabalho feminino é dificultado nas práticas sociais e intrafamiliares e a divisão sexual do trabalho é reafirmada pelas noções do que são "coisas de homem e coisas de mulher". As questões que emergem inter-relacionam pecuária, pobreza e gênero, pois grande parte das famílias participantes do Brasil Sem Miséria também está inserida na atividade pecuária. Questiona-se até que ponto a pecuária é atividade masculina e se a pobreza seria um "parâmetro" para caracterizar atividades rurais, inclusive a pecuária, como femininas?
\end{abstract}


Palavras-chave: Pecuária familiar. Divisão sexual do trabalho. Mulheres.

\title{
Productive inclusion, family livestock situation of rural women of brazil without poverty program in a municipality of the rs - context a little-known reality
}

\begin{abstract}
The aim of this article is to describe and analyze sociodemographic characteristics of rural women working in family livestock, inserted in Brazil without Poverty Plan in Encruzilhada do Sul. This type of work is culturally defined as masculine as well, the question is how women in it operate. In Rio Grande do Sul, the southern half has in beef cattle the main productive activity which alludes to a supposed production homogeneity. This condition challenges and boost research that shows the multiplicity of experiences of livestock rural families. Thus, the motivation of this article also is based on the problem of discussion little debated on family livestock, for example, the sexual division of labor and women's participation in the activity. So it was found the presence of women in family livestock and their inclusion in the Brazil without Poverty Program. The information analyzed shows that $92.31 \%$ of ownership in the program are women, $6.59 \%$ of men and $1.10 \%$ for both. This reality leads the female role of idea in action, however it is necessary to consider other issues that contribute to other explanatory possibilities of this condition. The trajectory and the sexual division of labor "earmarking" women to the most precarious jobs, it may be a potential answer. Thus, the recognition of women's work is hindered in social practices and intra-family and sexual division of labor is reaffirmed by the notions of what is "man of affairs and women's things". The issues that emerge interrelate livestock, poverty and gender, since most of the families of the Brazil without Poverty is also included in the livestock. We question the extent to which livestock is male activity and poverty would be a "parameter" to characterize rural activities, including livestock, as female?
\end{abstract}

Keywords: Family livestock. Sexual Division of Labor. Women.

\section{Inclusión productiva, ganadería familiar y situación de las mujeres rurales del programa brasil sin miseria en un municipio del rs - contexto de una realidad poco conocida}

\section{Resumen}

El objetivo principal de este artículo es describir y analizar características sociodemográficas de mujeres rurales actuantes en la ganadería familiar, insertadas en el Plan Brasil sin Miseria en Encruzilhada del Sur. Esta modalidad de trabajo es culturalmente definida como masculina, así, se cuestiona cómo las mujeres en ella se insertan. En el Río Grande do Sul, la Mitad Sul tiene en la ganadería de corte su actividad productiva principal lo que alude a una supuesta homogeneidad productiva. Esta condición desafía e impulsa investigaciones que demuestren la multiplicidad de las vivencias de las familias rurales ganaderas. De esta forma, la motivación de este artículo también se fundamenta en la discusión de problemáticas poco debatidas sobre la ganadería familiar, como por ejemplo, la división sexual del trabajo y la participación femenina en la actividad. Así se constató la presencia de mujeres en la ganadería familiar y su inserción en el Programa Brasil Sin Miseria. Las informaciones analizadas muestran que el $92,31 \%$ de la titularidad en el Programa es de mujeres, el 6,59\% de hombres y el 1,10\% de ambos. Esta realidad remite la idea de protagonismo femenino en la acción, sin embargo hay que considerar otras cuestiones que contribuyen a otras posibilidades explicativas de esa condición. La trayectoria y la división sexual del trabajo "destinando" a las mujeres a los trabajos más precarios, es posible que sea una respuesta potencial. De esta forma, el reconocimiento del trabajo femenino es dificultado en las prácticas sociales e intrafamiliares y la división sexual del trabajo es reafirmada por las nociones de lo que son "cosas de hombre y cosas de mujer". Las 
Inclusão produtiva, pecuária familiar e situação das mulheres rurais do Programa Brasil Sem Miséria em um município do RS - contexto de uma realidade pouco conhecida

cuestiones que emergen interrelacionan pecuaria, pobreza y género, pues gran parte de las familias participantes de Brasil Sin Miseria también está inserta en la actividad pecuaria. ¿Hasta qué punto la ganadería es actividad masculina y si la pobreza sería un "parámetro" para caracterizar actividades rurales, incluso la ganadería, como femeninas?

Palabras clave: Ganadería familiar. División sexual del trabajo. Mujeres.

\section{Introdução}

Este artigo busca descrever e analisar realidades vivenciadas no rural que, frequentemente, são invisibilizadas e não estimulam estudos acadêmicos. Refere-se à atividade pecuária familiar como uma dessas realidades, especialmente, ao tratar das mulheres inseridas na mesma. As assimetrias de gênero evidenciam desigualdades, dentre outras formas, na divisão sexual do trabalho masculino e feminino. Trata-se de uma discussão inicial, exploratória e descritiva de um projeto de dissertação de mestrado, vinculado ao Programa de Pós-Graduação em Desenvolvimento Rural/UFRGS, voltado à compreensão e conhecimento da situação de mulheres em atividades de trabalho na pecuária familiar.

A visão homogênea produzida/reproduzida do rural gaúcho remete à sociedade uma perspectiva estática da realidade do Rio Grande do Sul. Ou seja, remete-se ao Sul do Estado, à atividade pecuária como sinônimo de prosperidade, riquezas, grandes propriedades e, ao Norte, propriedades pequenas sustentadas na agricultura familiar originada de dinâmicas produtivas e familiares de imigrantes europeus. Esse olhar foi construído a partir da ocupação fundiária e fatos históricos.

A imagem transmitida divide o Estado em Metade Sul e Metade Norte, baseando-se, fundamentalmente, no tamanho dos estabelecimentos rurais. Isso ilustra que a viabilidade de um estabelecimento agropecuário estaria atrelada à distribuição de terras. No entanto, o que se constata na estrutura agrária gaúcha ultrapassa essa visão, ou seja, a estratificação social e econômica abarca múltiplas dimensões além da distribuição fundiária (COTRIM, 2003).

Outra associação presente no imaginário social expõe a figura do gaúcho como o homem valente, condutor da pecuária de corte, tida como principal atividade econômica em inúmeras propriedades. A mulher fica com as responsabilidades do lar. Essa divisão do que pertence ou representa a mulher e o que representa o homem gaúcho é percebida na construção do tradicionalismo gaúcho, pois como expõe Becker (2010, p.7), "o homem viril, montado em seu cavalo" é visto como o oposto da mulher, "desenhada" por condições físicas propícias para os afazeres domésticos, artesanato, culinária e cuidado com os filhos.

Contudo, a realidade apresenta incontáveis variações do preestabelecido culturalmente, pois as transformações político-sociais e econômicas moldam e adaptam as configurações produtivas, culturais e socioeconômicas no espaço e tempo (MATTE; WAQUIL; NESKE, 2014). As constantes mudanças citadas contribuem na desconstrução e reconstrução do imaginário que foca o homem como detentor dos saberes das atividades do campo. Entretanto, tornar a mulher rural visível no ambiente produtivo, mesmo que pareça tarefa superada, é atual e uma tarefa não muito simples.

A divisão sexual do trabalho demonstra as dificuldades em legitimar a mulher rural como sujeito produtivo, ainda mais ao tratar-se de uma atividade 
culturalmente definida como masculina. Isso se dá, sobretudo, em ambientes rurais familiares, onde a presença de "complementaridade" entre tarefas femininas e masculinas é enfatizada. Por conseguinte, em função da lógica dominante, no mercado de trabalho ou em ambientes de produção, a posição, intrafamiliar, subalterna reconhecidamente feminina é reproduzida e materializada, por exemplo, em salários menores (BRUMER, 1988).

A partir disso, busca-se, neste artigo, contribuir para a quebra de paradigmas e permitir a visibilidade de situações e condições vivenciadas por mulheres rurais em cenários distintos dos enquadrados no construto social, especificamente ao tratar-se da pecuária no Rio Grande do Sul. Também objetiva-se possibilitar outros olhares além da relação sócio-histórica "fundamentalista" entre a pecuária e a figura masculina.

Com base nisso, o ambiente empírico pesquisado reflete essa realidade. Trata-se do Município de Encruzilhada do Sul, inserido na Serra do Sudeste, na Metade Sul do Rio Grande do Sul, que tem sua formação histórica e socioeconômica baseada na pecuária de corte e na imagem do gaúcho (MATTE; WAQUIL; NESKE, 2014). A inserção no Plano Brasil sem Miséria permitiu a identificação de famílias rurais, praticantes da pecuária de corte, enquadradas em situação de extrema pobreza. Nesse sentido, em um primeiro momento, descreve-se características sociodemográficas e econômicas de mulheres rurais inseridas no Plano Brasil sem Miséria em Encruzilhada do Sul, incluindo algumas informações produtivas, no intuito de conhecer a realidade pesquisada.

Além desta introdução, este artigo apresenta algumas características do ambiente empírico, breve explanação sobre a politica pública "Plano Brasil sem Miséria" e os encaminhamentos para análise dos dados apresentados. A segunda parte expõe a discussão desenvolvida em dois momentos: apresentação de características das/dos participantes do Brasil Sem Miséria e as especificidades que identificam parte dos beneficiários como pecuaristas familiares.

\section{2 "Outros olhares" sobre a pecuária familiar e gênero}

A Metade Sul do Rio Grande do Sul, conhecida por desenvolver a pecuária de corte, passa a ser reconhecida como tal a partir de meados da década de 1980. Os esforços acadêmicos e políticos, apoiados na histórica decadência econômica e social da região frente ao Estado, institucionalizaram-na e despertaram a atenção do poder público. As políticas públicas desenvolvidas objetivavam a reconversão produtiva e econômica da região (CARGNIN, 2014). Entretanto, observa-se que a aptidão sociocultural para a histórica pecuária de corte se faz persistente. $O$ Programa de Fomento e Reconversão Produtiva da Metade Sul-RECONVERSUL, no período de 1996-1998, atuou como ferramenta na "recuperação" da região, e ainda reafirmou a importância da pecuária, pois mais de $40 \%$ dos recursos ao setor primário foram destinados à criação de bovinos (CARGNIN, 2014). Contudo, a discussão dicotômica (Metade Norte/Sul) na agenda política perde a intensidade e abre espaço para outras interpretações das desigualdades regionais, porém o reconhecimento cultural da divisão do Estado em duas partes é inegável para a sociedade sul-rio-grandense. (CARGNIN, 2014).

É justamente esse reconhecimento, especialmente da Metade Sul, que 
Inclusão produtiva, pecuária familiar e situação das mulheres rurais do Programa Brasil Sem Miséria em um município do RS - contexto de uma realidade pouco conhecida

impulsiona a necessidade de identificar características específicas de famílias rurais praticantes da atividade pecuária de corte. A iniciativa se dá com pesquisas realizadas pela Associação Riograndense de Empreendimentos de Assistência Técnica e Extensão Rural-Emater RS, originadas em 1999/2000, que reconhecem a importância de legitimar como categoria social os chamados pecuaristas familiares. Essa necessidade se deu, justamente pela dificuldade de encontrar agricultores familiares na Metade sul do Rio Grande do Sul, ou seja, um cenário onde a grande propriedade é reconhecida como sistema produtivo característico. (RIBEIRO, 2009).

Diante disso, surgem pesquisas com a finalidade de tornar visível a heterogeneidade da pecuária de corte gaúcha. O habitual desconhecimento da múltipla e complexa realidade da pecuária no Rio Grande do Sul impulsionou os estudos de caracterização dos perfis de produtores, permitindo sua visualização e aproximação de potenciais ações intervencionais. (PORTO, 2008). Esses estudos motivam pesquisadores a aprofundarem-se em diversas problemáticas vivenciadas por essas famílias com o intuito de expô-las, instigando novas pesquisas e iniciativas que as beneficiem positivamente.

Além de pesquisas focadas na pecuária familiar, a Metade Sul do Rio Grande do Sul instiga pesquisadores a investigar o rural e o seu desenvolvimento em função de constatações que delineiam a região como socioeconomicamente marginalizada. Um exemplo é o PROINTER do Programa de Pós-Graduação em Desenvolvimento Rural, o qual a partir de uma proposta interdisciplinar, objetiva explorar a complexa diversidade rural de um espaço definido por suas dinâmicas socioeconômicas, naturais e tecnológicas. (BECK et al, 2011).

A presença de Encruzilhada do Sul (figura 1) nos oito municípios de estudo do PROINTER mostra que o uso do solo em atividades agrossilvopastoris é baixo para lavouras e alto para pastagens e reflorestamentos, evidenciando a atual presença da pecuária. A situação técnica-agrícola apresenta baixo rendimento na pecuária e situação oposta à agricultura, assim como pouca mecanização e alto uso de mão de obra; a situação econômica é considerada precária (BECK et al, 2011).

A grande extensão territorial do município, $3.348,319 \mathrm{Km}^{2}$, possibilita a visualização dos sistemas produtivos característicos (bovinos, ovinos, silvicultura, entre outros), assim como, induz a reflexão da diversidade encontrada no rural. Em termos de população, aproximadamente $29 \%$ (7.415) são residentes no rural e o total de habitantes estima-se em 25.563. A taxa de urbanização para as mulheres (72,5\%) é mais elevada em relação aos homens (67\%) (IBGE, 2010).

Ao analisar o trabalho no rural, o percentual de homens com 16 anos ou mais ocupados em atividades na agricultura é de 52,9\%, a maior taxa dentre os demais setores, já as mulheres na mesma condição representam $27,8 \%$. O setor que mais emprega mulheres em Encruzilhada do Sul é o de serviços, ou seja, 66\% das ocupações femininas. (IBGE, 2010). Esses dados podem representar a desvalorização do trabalho feminino na agricultura, por exemplo, ao não considerar as atividades domésticas como pertencentes ao setor, reafirmando a presença masculina como propícia ao desenvolvimento das atividades consideradas como "produtivas" no rural. Resta para as mulheres as "improdutivas" atividades domésticas, o que, ao mesmo tempo, invisibiliza e destitui de valor esse trabalho e não considera o que é desenvolvido nesse âmbito, como as atividades com a criação e a produção na agricultura. 
Marta Julia Marques Lopes, Tatielle Belem Langbecker 
Inclusão produtiva, pecuária familiar e situação das mulheres rurais do Programa Brasil Sem Miséria em um município do RS - contexto de uma realidade pouco conhecida

Figura 1. Localização do Município de Encruzilhada do Sul

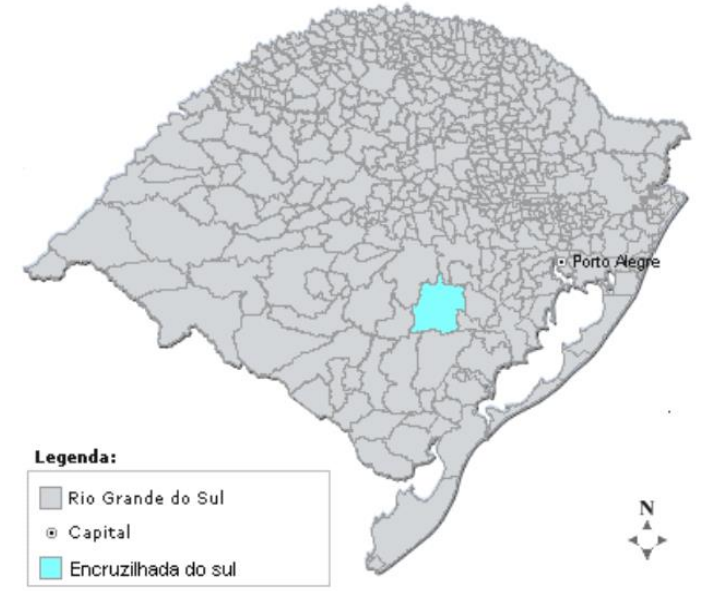

Fonte: Feedados, 2015.

Essas constatações fundamentam a ideia de discutir problemáticas até então pouco debatidas no que se refere à pecuária familiar, ou seja, a divisão sexual do trabalho e suas especificidades.

Alguns dados encontrados não permitem visualizar a presença de mulheres, especificamente, na pecuária familiar ao se referir às criações de ovinos e bovinos em Encruzilhada do Sul. Contudo, há a indicação de que 142 estabelecimentos rurais referem mulheres produtoras em atividades econômicas de pecuária e criação de outros animais, o que potencializa a possibilidade de encontrá-las. (IBGE, 2006).

Nesse sentido, contatos realizados com a Secretaria da Agricultura do município encaminharam-nos à Emater local, cujos extensionistas confirmaram a presença e a participação de mulheres na pecuária familiar. Na oportunidade, foi mencionada a inserção de mulheres, envolvidas com a pecuária, no Plano Brasil Sem Miséria. O intuito desse Plano é a superação da pobreza extrema, identificada pelo indicador renda, ou seja, enquadram-se como famílias em extrema pobreza aquelas com renda mensal de até $\mathrm{R} \$$ 70,00 por pessoa. (BRASIL, 2015).

Contudo, em função de mudanças na metodologia de cálculo dos beneficiários do Bolsa Família, a condição de extrema pobreza foi superada, porém há outras dimensões, além da renda, que configuram a pobreza. Nesse sentido, o Plano foi construído em três diferentes eixos: garantia de renda, inclusão produtiva e acesso a serviços. Em se tratando de Encruzilhada do Sul, o eixo temático que compreendeu as mulheres inseridas na pecuária foi a inclusão produtiva por meio do fomento às atividades produtivas; além disso, há a participação de jovens no Pronatec (216 matrículas) e apoio da Assistência Técnica e Extensão Rural - ATER (100 famílias de agricultores familiares) (BRASIL, 2015).

No município, 92 famílias foram beneficiadas com o fomento. Cada uma recebeu até $\mathrm{R} \$ 2.400,00$ em três parcelas, a fundo perdido, para compra de equipamentos, insumos e/ou contratação de serviços de terceiros para a implantação de projetos produtivos (BRASIL, 2015). Dessa forma, a caracterização do perfil de mulheres rurais inseridas no Plano Brasil Sem Miséria em Encruzilhada do Sul se dá, justamente, a partir da pesquisa documental em questionários aplicados às famílias beneficiárias, denominados de diagnóstico da unidade produtiva família (EMATER, 2015), cedidos para consulta pela Emater do município, que totalizam 91 questionários. Esses questionários foram aplicados pela Emater, 
em momento anterior a esta pesquisa, como elemento de acompanhamento e caracterização das famílias contempladas com a ação.

Em termos metodológicos, a abordagem caracteriza-se como qualitativa apoiada em estudo de casos múltiplos, contando com a realização de algumas quantificações pertinentes à caracterização sociodemográfica descritiva da situação das mulheres pecuaristas familiares. Essas quantificações fizeram-se necessárias pelo desconhecimento objetivo do perfil de mulheres implicadas na atividade da pecuária familiar no município. Não existiam fontes secundárias disponíveis que caracterizassem essa população de mulheres trabalhadoras. Dessa forma, a pesquisa apresenta características da pesquisa documental que, em acordo com Gil (2008), assemelham-se à pesquisa bibliográfica; a principal distinção, entretanto, está nas fontes a serem consultadas, pois a pesquisa documental investiga materiais ainda não analisados, podendo ser documentos de primeira mão (documentos oficiais, reportagens, fotografias, etc.) ou segunda mão (relatórios, tabelas, etc.). Nesse sentido, os documentos analisados nesta pesquisa foram inéditos no que se refere à temática descrita.

Com isso, busca-se analisar realidades do rural nas quais as mulheres estão presentes e sua atuação. A intenção é compreender sua importância na perspectiva do desenvolvimento para localidades rurais. Assim, a adoção da perspectiva de gênero em análises de situações/condições rurais possibilitou o conhecimento e compreensão de maneira mais abrangente do vivenciado no rural, proporcionando um olhar sobre as desigualdades entre homens e mulheres nas múltiplas dimensões presentes no cotidiano (NARCISO; HENRIQUES, 2008).

Apesar das transformações econômicas, demográficas e culturais decorrentes da consolidação do capitalismo, produzidas nas vidas das populações, especialmente ao referir-se às mulheres, a materialização das desigualdades entre homens e mulheres é diariamente consolidada pela reduzida participação política, menor controle sobre bens materiais, remunerações menores no trabalho em relação aos homens, múltiplas formas de violência (CAMPOS, 2011), dentre outros exemplos, indicando a persistência das desigualdades de gênero.

A autora também destaca a importância de análises a partir da perspectiva de gênero, pois revela as bases materiais e simbólicas que constituem as desigualdades de gênero, possibilitando desnaturalizar a opressão feminina e ainda explicitar as características históricas e socioculturais atribuídas aos homens e às mulheres. (CAMPOS, 2011).

Com base nisso, é pertinente mencionar a compreensão das dimensões de gênero que se adota neste artigo, no intuito de direcionar a leitura à ótica de análise pretendida. Assim, as análises baseiam-se nos estudos de Scott (1995, p. 21). A autora define o gênero sustentado em duas proposições, ou seja, "um elemento constitutivo de relações sociais baseado nas diferenças percebidas entre os sexos", e o gênero como "uma forma primeira de significar relações de poder".

A relação das duas partes principais da constituição do gênero trazidas por Scott (1995) denota nitidamente a dependência de uma a outra, ou seja, o poder presente nas relações de gênero fundamenta-se nas diferenças percebidas biologicamente. Isso implica a compreensão de que as estruturas hierárquicas se baseiam em relações "naturalmente" estabelecidas entre homens e mulheres. 
Inclusão produtiva, pecuária familiar e situação das mulheres rurais do Programa Brasil Sem Miséria em um município do RS - contexto de uma realidade pouco conhecida

Dessa forma, a definição de gênero pode servir como elemento para a explicação da persistência de desigualdades entre homens e mulheres. No entanto, o intuito não seria excluir as diferenças entre os sujeitos, mas apontar que tais diferenças são empregadas como argumento para sustentar tratamentos desiguais. (LOURO, 1996). Nessa base, assentam-se as hierarquias entre homens e mulheres, entre trabalho feminino e trabalho masculino, por exemplo.

Nessa perspectiva, o gênero como categoria analítica revela-se com potencial para explorar as relações de desigualdades inseridas no rural e mais especificamente no ramo pecuário. Especialmente no rural, as assimetrias de gênero são bastante evidentes, pois, como diz Brumer (2004), culturalmente, a mulher é destinada a desempenhar determinadas atividades produtivas e reprodutivas e a conformar-se com a tradicional distribuição de poder e de acesso à terra, permanecendo em uma posição subordinada no ambiente familiar.

\section{Resultados e discussão}

\subsection{Mulheres e pobreza: faces da pecuária familiar}

A pecuária tem sido consolidada no imaginário social como sinônimo de grandes propriedades e desenvolvida pelos homens. Entretanto, ao se considerar as famílias participantes do Brasil Sem Miséria inseridas na pecuária, a situação de vulnerabilidade social foi destacada pelos agentes locais da Emater. Além de enquadrarem-se na condição de extrema pobreza, em grande parte, as propriedades estão localizadas a grandes distâncias da sede do município estudado, dificultando o acesso aos serviços básicos.

Em questionamento sobre as demandas trazidas por essas famílias até a instituição, a resposta revelou que, de modo geral, especialmente tratando da população extremamente pobre, não há demandas que se materializem em solicitações aos serviços. Algumas necessidades são apontadas pelos próprios técnicos, pois a situação de pobreza em que vivem, muitas vezes, impede a participação em instâncias de luta pelos direitos sociais. Essa constatação mostra perspectivas da pobreza que ultrapassam as recorrentes avaliações baseadas apenas na renda (sem desconsiderar sua relevância), ou seja, a pobreza como resultado de privações das capacidades básicas, onde essa privação é associada a "um nível mais fundamental - mais próximo das demandas informacionais da justiça social” (SEN, 2010, p. 123).

A situação de pobreza das famílias, após análise do diagnóstico da unidade produtiva familiar, ganha alguns contornos típicos presentes em situações semelhantes distribuídas pelo Brasil. Esse diagnóstico, aplicado às famílias pelos técnicos da Emater, visou caracterizar socioeconomicamente as famílias beneficiárias do Programa Brasil Sem Miséria, totalizando 91 questionários. A maioria dos diagnósticos tem como titulares as mulheres (92,31\%), enquanto os homens representam apenas $6,59 \%$ e $1,10 \%$ é a fatia em que ambos estão como titulares. Em um primeiro momento, a resposta acima pode ser entendida como satisfatória, remetendo ao protagonismo das mulheres, porém, ao verificar o porquê desta condição, o olhar recai sobre outras questões.

Os requisitos para acesso ao fomento de inclusão produtiva do Brasil Sem 
Miséria são: renda mensal de até $\mathrm{R} \$$ 70,00 por pessoa, registro no Cadastro Único e portar a Declaração de Aptidão ao Pronaf - DAP. O pagamento dos recursos são realizados por meio do cartão do Bolsa Família ou pelo Cartão Cidadão (BRASIL, 2013). Nessa situação, encontra-se, talvez, o principal "porquê": o registro no Cadastro Único - Cadúnico enquadra famílias pobres e extremamente pobres com até meio salário mínimo por pessoa no intuito de gerar informações para potencializar políticas públicas na melhoria de vida, e o recebimento por meio do cartão do Bolsa Família, programa acessado por meio do Cadúnico.

O argumento de gênero que se analisa está respaldado na condição feminina da pobreza cada vez mais crescente em algumas regiões do Brasil. Isso se dá pelas desigualdades históricas de gênero que, majoritariamente, atribuem trabalhos mais precários às mulheres, acentuando a invisibilidade feminina e estabelecendo "padrões" que constituem e sedimentam a divisão sexual do trabalho. Dessa forma, as políticas de combate à pobreza no Brasil, especialmente o Bolsa Família, focam-se nos pobres e abrem espaço para um recorte de gênero, pois são as mulheres que recebem o dinheiro (CAMPOS, 2011). Assim, mesmo que a mulher esteja "à frente" do cadastramento numérico, no caso do diagnóstico da unidade produtiva, não significa que ela efetivamente conduza, em termos econômicos, a família. Provavelmente reflita mais um indicativo do "sexo da pobreza".

Contudo, é indispensável destacar que o diagnóstico em discussão revelou dois casos em que o estabelecimento não mostrava a presença de mulheres e, oito, em que não havia homens, ou seja, quando o assunto é pobreza, a face feminina ganha espaço, seja no rural ou urbano. Essas evidências mostram a situação feminina no rural e identificam algumas das transformações sociodemográficas percebidas no País, como, por exemplo, o aumento do número de estabelecimentos chefiados por mulheres. A chefia familiar feminina passa a ser atrelada às condições de pobreza acentuada, assim como precariedade social conduzindo ao entendimento de que as possibilidades de rendimentos financeiros são menores nesses casos do que em famílias com a presença do casal (LOMBARDI, 2009).

A caracterização sociodemográfica dos sujeitos imersos na extrema pobreza tem contribuído substancialmente nos delineamentos de políticas públicas. A faixa etária e sua relação com o gênero é um importante indicador na definição dessas ações. Assim, por exemplo, dados apresentados abaixo (Tabela 1) indicam a presença de mulheres, beneficiárias do Brasil Sem Miséria na modalidade de fomento à inclusão produtiva em Encruzilhada do Sul, mais jovens comparadas aos homens na mesma situação.

Tabela 1. Idade dos beneficiários do fomento à inclusão produtiva - Brasil Sem Miséria em Encruzilhada do Sul 2012/2013

\begin{tabular}{lcccc}
\hline \multicolumn{1}{c}{ Idade } & \multicolumn{2}{c}{ Mulher } & \multicolumn{2}{c}{ Homem } \\
\hline Até 30 anos & Valor Absoluto & Valor Relativo & Valor Absoluto & Valor Relativo \\
De 31 a 40 & 14 & $15,73 \%$ & 6 & $7,23 \%$ \\
De 41 a 50 & 23 & $25,84 \%$ & 12 & $14,46 \%$ \\
De 51 a 60 & 34 & $38,20 \%$ & 30 & $36,14 \%$ \\
De 61 a 70 & 18 & $20,22 \%$ & 29 & $34,94 \%$ \\
Total & 0 & $0 \%$ & 6 & $7,23 \%$ \\
\hline
\end{tabular}

Fonte: Emater Encruzilhada do Sul, 2015, elaborado pelas autoras. 
Inclusão produtiva, pecuária familiar e situação das mulheres rurais do Programa Brasil Sem Miséria em um município do RS - contexto de uma realidade pouco conhecida

A média de idade das mulheres é de 42,19 anos, a idade mínima é 21 anos e a máxima, 59 anos. Em relação aos homens, a idade média é de 47,33 anos, a mínima também corresponde a 21 anos e a máxima alcança os 64 anos.

As faixas etárias demonstram mais claramente a diferença de idade entre mulheres e homens, pois $79,77 \%$ das mulheres encontram-se com até 50 anos e os homens na mesma situação representam 57,83\% da população masculina. A presença de mulheres de até 30 anos corresponde a mais que o dobro quando refere-se aos homens da mesma idade. Essa configuração remete ao estudo de Rauber (2010), em que a autora apresenta um panorama da masculinização do campo nas diferentes regiões do Rio Grande do Sul.

A constatação central de Rauber (2010) evidenciou as relações de produção e os sistemas produtivos como potenciais definidoras dos processos de masculinização no campo. Em análise inicial, foram avaliados os índices de masculinidade na década de 1950, nos quais as propriedades mais fragmentadas representariam um índice de masculinidade inferior às propriedades caracterizadas pela pecuária extensiva, na maioria das regiões. Entretanto, uma das regiões que fornece elementos questionadores dessa constatação citada é justamente a Serra do Sudeste, onde situa-se o Município de Encruzilhada do Sul. Rauber (2010) destaca que, apesar da região caracterizar-se pela pecuária extensiva, a presença de dinâmicas familiares de produção reduz os índices de masculinização. Talvez esteja nesse contexto histórico, uma explicação para o maior percentual de mulheres mais jovens em relação aos homens. A autora também avaliou o índice em relação à faixa etária, resultando em uma proporção de 119,79 homens para cada 100 mulheres, correspondendo ao maior número de homens mais velhos em relação às mulheres, conforme a tabela 1.

A discussão sobre o êxodo rural seletivo talvez possa explicar parte da realidade exposta, pois, conforme Brumer (2004), as diferenças entre as idades da população nas regiões do Estado, podem resultar das distintas condições de vida e trabalho no rural. A divisão sexual do trabalho e a invisibilidade do trabalho feminino, percebido como mera "ajuda", impulsiona em vários casos a saída de mulheres do rural em busca de promoção socioeconômica. Dentre as possibilidades de explicação, neste caso da diferença de faixa etária entre os sexos, percebe-se que entre as famílias extremamente pobres no rural de Encruzilhada do Sul pode haver a associação entre sexo e idade, pois também observa-se que o valor absoluto de mulheres (89) é maior que o de homens (83), mostrando a maior participação de mulheres como responsáveis pelos estabelecimentos e, reforçando a figura da mulher em meio à pobreza rural.

A escolaridade é um importante indicador na caracterização de perfis, ainda mais ao considerá-la na perspectiva de gênero, pois possibilita uma análise de desigualdades vivenciadas no cotidiano das práticas sociais que, constantemente, buscam sua dispersão no aumento relativo do tempo de estudo das mulheres. A tabela 2 abaixo permite identificar a baixa escolaridade dos sujeitos inseridos na condição de extrema pobreza, independente de sexo. 
Tabela 2. Escolaridade dos beneficiários do fomento à inclusão produtiva - Brasil Sem Miséria em Encruzilhada do Sul 2012/2013

\begin{tabular}{lcccc}
\hline \multicolumn{1}{c}{ Escolaridade } & \multicolumn{2}{c}{ Mulher } & \multicolumn{2}{c}{ Homem } \\
\hline Analfabeto & Valor Absoluto & Valor Relativo & Valor Absoluto & Valor Relativo \\
Alfabetizado & 6 & $6,74 \%$ & 7 & $8,43 \%$ \\
E. F. Incompleto & 2 & $2,25 \%$ & 4 & $4,82 \%$ \\
E. F. Completo & 73 & $82,02 \%$ & 65 & $78,31 \%$ \\
E.M. Incompleto & 4 & $4,49 \%$ & 4 & $4,82 \%$ \\
E. M. Completo & 3 & $3,37 \%$ & 1 & $1,20 \%$ \\
Não respondeu & 1 & $1,12 \%$ & 0 & $0,00 \%$ \\
Total & 0 & $0,00 \%$ & 2 & $2,41 \%$ \\
\hline
\end{tabular}

Fonte: Emater Encruzilhada do Sul, 2015 elaborado pelas autoras.

Mesmo com o reduzido número de anos de estudo, a comparação entre homens e mulheres mostra a escolaridade feminina maior do que a masculina. $O$ percentual de mulheres analfabetas, ou somente alfabetizadas, corresponde a $8,99 \%$, enquanto, para os homens inseridos na mesma situação, o percentual está em 13,25\%. Considerando a população com escolaridade equivalente ao ensino fundamental incompleto, a relação se confirma, já que o percentual de mulheres $(82,02 \%)$ é superior ao de homens (78,31\%).

Agregando o ensino fundamental completo, ensino médio incompleto e completo, tem-se $8,98 \%$ das mulheres e $6,02 \%$ dos homens, e outros $2,41 \%$ que não responderam dentre os homens. Assim, a escolaridade baixa é percebida como um fenômeno que alcança as diversas realidades brasileiras e delineia uma das grandes preocupações no rural (MELO; DI SABBATO, 2006). Em contrapartida, uma das principais mudanças observadas se refere ao aumento da escolaridade feminina comparada à masculina (LOMBARDI, 2009). Na análise censitária realizada por Lombardi (2009), que compreendeu o período de 1993 a 2006, além do aumento da escolaridade feminina, verificou-se a permanência da baixa escolaridade em áreas rurais.

Na perspectiva economicista, pensar na ascensão de escolaridade para os sujeitos é pensar na acumulação de capital humano e nos consequentes resultados, especialmente econômicos, que esta permitirá alcançar. Ou seja, quanto maior escolaridade, maior serão seus resultados produtivos em sua atividade laboral, revertendo os ganhos em expansão econômica. Todavia, abordagens teóricas como a proposta por Sen (2010, p. 372) permitem análises que incluam outros elementos além dos que convertem-se em valores físicos, isto é, a perspectiva seniana alude à capacidade humana (e não ao capital humano) e a liberdade substantiva das "pessoas para levar a vida que elas têm razão para valorizar e para melhorar as escolhas que elas possuem".

Essa abordagem suporta interpretações que contribuem para a compreensão de fatores como a escolaridade, que beneficiem as pessoas não apenas economicamente. Nesse sentido, a escolaridade vai além do acúmulo de capital humano convertido em mais produção; a escolaridade permite, por exemplo, maior argumentação em defesa de interesses, maior amplitude das possibilidades de escolha por meio das informações. (SEN, 2010).

Nesse sentido, a abordagem não exclui a importância do capital humano, 
Inclusão produtiva, pecuária familiar e situação das mulheres rurais do Programa Brasil Sem Miséria em um município do RS - contexto de uma realidade pouco conhecida

mas vincula a ele a relevância em considerar as capacidades humanas. Isso remete à importância desses elementos para analisar a escolaridade das mulheres rurais, pois, se o pensamento se voltasse apenas ao capital humano, na realidade presente permeada por desigualdades de gênero, somente o "acúmulo" de capital humano não seria suficiente na promoção socioeconômica feminina. Porém, como há mais o que considerar, as capacidades humanas abrem portas para a promoção social, cultural e econômica dos sujeitos. Assim, o aumento da escolaridade feminina no rural colabora para a expansão das capacidades humanas e, consequentemente, para as liberdades de escolha.

Dentre os dados analisados, 78,02\% dos participantes possuem filhos e $21,98 \%$, não possuem. Destes últimos, $80 \%$ correspondem a casais que não têm filhos e os $20 \%$ restantes dividem-se em $10 \%$ de homens sozinhos e mulheres na mesma condição. A média do número de filhos é de 1,62, e o mínimo está representado por aqueles que não têm filhos e o máximo seis filhos, apenas em uma situação, e mais de três filhos evidenciou-se em dez casos.

Essa configuração é semelhante à encontrada por Lombradi (2009). A autora, baseada em dados do Instituto Brasileiro de Geografia e Estatística -IBGE, constatou que, a partir da década de 1970, a taxa de fecundidade no Brasil apresentou um ritmo decrescente. No ano de 1990, o número de filhos por mulher era de 2,79 e, em 2008, reduziu para 1,86. Conforme a autora, isso refletiu em duas tendências: redução do tamanho das famílias, permitindo maiores chances para a inserção de mulheres no mercado de trabalho e variação no desenho dos arranjos familiares, assim como o crescimento do número de famílias chefiadas por mulheres.

É importante ressaltar a presença e o número de filhos como variáveis intrafamiliares fundamentais para a determinação das diferentes formas de inserção na cadeia produtiva da carne, por exemplo. A presença de filhos contribui significativamente na mão de obra utilizada no estabelecimento, assim como na prática de atividades não agrícolas e outras atividades, além da pecuária de corte, e ainda contribui para algumas das explicações sobre as diferentes maneiras de comercialização, ou não, das unidades familiares (SANDRINI, 2005).

A proporção de filhos homens é de $57,43 \%$, enquanto que as mulheres representam $42,57 \%$ da prole dos participantes. No rural, a relação de mais filhos homens do que mulheres já é conhecida. Destacam Melo e Di Sabbato (2009) que o processo de permanência masculina no campo em consonância com a migração feminina para as cidades está cada vez mais crescente, sendo que a conhecida desvalorização das mulheres e do trabalho feminino, certamente, está presente nos casos de êxodo das mulheres do campo.

A seletividade do êxodo rural por idade e sexo tem sido discutida por vários autores e se apresentado como um fenômeno de grande alcance. Em termos da migração da juventude em geral, vários motivos a circundam, como as oportunidades escassas para a inserção no ambiente econômico independente dos pais e a divisão do trabalho e sua respectiva invisibilidade. Já em relação ao gênero, a tradição em separar as atividades femininas como "ajuda" e atribuir maior valor às atividades produtivas masculinas, assim como a exclusão frequente das mulheres da herança, são algumas das circunstâncias que conduzem o êxodo rural feminino em direção às cidades (BRUMER, 2004). 
$\mathrm{Na}$ análise das características da pecuária familiar, um elemento que chama a atenção de diversos autores são as fontes de renda advindas de atividades não agrícolas, ou outras atividades, além da pecuária de corte. Nesse aspecto, as especificidades encontradas confirmam-se na realidade analisada, já que todos os componentes familiares são beneficiários do Bolsa Família. No que tange a aposentadoria, os questionários investigados apontam que nenhuma dessas mulheres recebe aposentadoria, enquanto que $7,69 \%$ dos familiares recebem 0 benefício.

Considerando as constatações anteriores sobre a presença de filhos nos estabelecimentos e relacionando-a com o recebimento de rendas extras, destaca-se a importância das rendas não agrícolas, pois a existência de filhos intensifica a necessidade de consumo da família. Dessa forma, se a renda agrícola não é suficiente para o suprimento dessas necessidades, "a renda não agrícola, neste caso, acaba sendo um recurso importante para o sustento da unidade familiar" (SANDRINI, 2005, p. 97).

Outro ponto pertinente de análise é a integração social das mulheres participantes do programa. Verifica-se, na Tabela 3 abaixo, que o tipo de organização com mais participação feminina são as associações comunitárias com 26,97\% das mulheres. Em segundo lugar, estão as igrejas, representando 11,24\% da participação social. Na sequência, com o mesmo percentual (2,25\%), estão mulheres inseridas em grupos informais e as que não responderam. No percentual de $1,12 \%$, existem três casos que correspondem à participação em grupos de mulheres, igreja e associação comunitária e grupos de mulheres e associação comunitária.

Tabela 3. Integração social das mulheres beneficiárias do fomento à inclusão produtiva - Brasil Sem Miséria em Encruzilhada do Sul 2012/2013

\begin{tabular}{lcc}
\hline Integração & Valor Absoluto & Valor Relativo \\
\hline Associação Comunitária & 24 & $26,97 \%$ \\
Igreja & 10 & $11,24 \%$ \\
Grupo Mulheres & 1 & $1,12 \%$ \\
Grupo Informal & 1 & $2,25 \%$ \\
Igreja e A. C. & 1 & $1,12 \%$ \\
A.C.e G. Mulheres & 1 & $1,12 \%$ \\
Nenhum & 48 & $53,93 \%$ \\
Não respondeu & 2 & $2,25 \%$ \\
Total & 89 & $100 \%$ \\
\hline
\end{tabular}

Fonte: Emater Encruzilhada do Sul, 2015, elaborado pelas autoras.

Entretanto, uma significativa fração refere-se àquelas que não participam de nenhum tipo de organização com intuito de integração social $(53,93 \%)$, isto é, mais da metade das mulheres inseridas no Programa Brasil sem Miséria no município não participam de nenhuma atividade integradora.

A importância da participação social feminina é mencionada por Martinez (2010) em sua tese, pois pode gerar mecanismos para a abertura de espaços onde os sujeitos exerçam seus direitos e construam qualitativamente e de maneira conjunta suas demandas. A autora ainda salienta que a participação em organizações, de diferentes tipos permite múltiplas estratégias de subsistência, 
Inclusão produtiva, pecuária familiar e situação das mulheres rurais do Programa Brasil Sem Miséria em um município do RS - contexto de uma realidade pouco conhecida

que, em alguns casos, contribuem para a retirada de famílias da situação de extrema pobreza. Nessa perspectiva, faria sentido a relação da baixa integração social das mulheres inseridas no programa, já que estão enquadradas na condição de extrema pobreza.

Contudo, é fundamental considerar outras óticas, pois a condição de extrema pobreza não pode ser entendida como resposta exclusiva para a não participação feminina em organizações sociais. Nesse sentido, a perspectiva de Sen (2010) suscita algumas possibilidades, pois as privações de liberdade limitam as escolhas e as oportunidades das pessoas em exercer sua condição de agente, ou seja, as condições e situações vivenciadas pelos sujeitos atuam como definidoras das possibilidades de escolha e de acesso, podendo acrescentar, em participar ou não de atividades diversas, por exemplo, organizações sociais.

Por outro lado, $43,82 \%$ das participantes do programa estão inseridas em alguma forma de integração social e podem ser consideradas como geradoras de capital social das famílias. Conforme a análise de Martinez (2010, p.53), o capital social pode ser percebido "como um conjunto de recursos disponíveis na estrutura da sociedade e dos quais os sujeitos podem dispor mediante suas redes e instituições, necessariamente imbricadas ao seu sistema de normas e valores".

A participação feminina no que se denomina integração social também pode ser vista como ruptura com realidades historicamente constituídas, pois as conduz a ultrapassarem barreiras do espaço doméstico e direcionarem-se aos espaços públicos de interação. Essas rupturas estão intimamente ligadas à produção e à acumulação de capital social, colaborando na promoção de programas e projetos e aproximando as realidades às diversas formas do desenvolvimento comunitário. A conquista por políticas de saúde e educação no rural, por exemplo, é resultado, do capital social e do empenho das organizações de mulheres, já que os homens, em grande maioria, estão envolvidos com atividades economicamente produtivas (MARTINEZ, 2010).

A partir das informações apresentadas, verificam-se algumas das características das mulheres no Brasil Sem Miséria em Encruzilhada do Sul no intuito de compreender sua posição como agentes em suas famílias. Também buscou-se analisar algumas dessas particularidades de gênero identificando as assimetrias entre os sexos. Assim, na sequência, pretende-se apontar especificidades que demarcam a pecuária familiar e assim contribuem para reconhecê-la nas famílias participantes do Brasil Sem Miséria em Encruzilhada do Sul. A tentativa se dá no sentido de compreender a presença e participação de mulheres na atividade da pecuária familiar.

\subsection{A relação entre a pecuária familiar e as atividades desenvolvidas pelas participantes do brasil sem miséria}

A pecuária familiar revela características próprias, expressas em traços históricos, que a definem desta forma, bem como explicitam a necessidade de iniciativas que compreendam sua lógica produtiva com o propósito de continuidade em espaço e tempo. Em vista disso, buscou-se aproximar analiticamente essas características às observadas nos dados analisados no intuito de contribuir para o conhecimento das suas múltiplas faces. 
Cabe ressaltar que as constantes mudanças conjunturais ocorridas nos sistemas produtivos no Rio Grande do Sul, especialmente nas Microrregiões da Serra do Sudeste e Campanha Meridional, apontam para a inserção plural de atividades produtivas, ao mesmo tempo em que a pecuária prevalece. Todavia, o espaço anteriormente destinado à pecuária fraciona-se para dar lugar às demais atividades, como lavouras de soja, arroz e trigo, silvicultura, fruticultura, entre outras (MATTE; WAQUIL; NESKE, 2014).

As atividades produtivas desenvolvidas na propriedade são um dos principais indicativos da presença da pecuária familiar. De acordo com Ribeiro (2009), os pecuaristas familiares inicialmente foram definidos como agricultores familiares que criam bovinos de corte. A expressão, por vezes, não mostra claramente esse significado, já que a pecuária pode estar relacionada com a criação de outros animais, não somente de bovinos. Entretanto, nesse caso, refere-se aos pequenos produtores de bovinos de corte, incluindo a possibilidade de desenvolvimento de outras atividades.

Dentre as atividades produtivas desenvolvidas nos estabelecimentos correspondentes ao diagnóstico da unidade produtiva familiar, do qual tem-se tratado neste texto, $49,44 \%$ contam com a presença de bovinos e, acrescentando aquelas que possuem ovinos, sem a presença de bovinos, a representação chega a $62,92 \%$ dos estabelecimentos. A ovinocultura também está inserida nesse universo, visto que, nas definições da Emater, considera-se pecuarista familiar produtores que obtenham sua principal renda a partir da bovinocultura de corte e/ou ovinocultura, ou que estas atividades ocupem a maioria da área de seu estabelecimento (RIBEIRO, 2009).

Apenas 1,12\% das situações apresentadas desenvolvem exclusivamente a bovinocultura, os demais mesclam bovinos e/ou ovinos com outras atividades, como aves, suínos, equinos, sem ainda mencionar vacas de leite, plantação de milho, mandioca e feijão. Dessa maneira, a diversificação das atividades na propriedade rural tende a assegurar uma atividade produtiva às mulheres, desde que essas atividades possibilitem constantemente a ocupação da mão de obra familiar durante o ano e garanta renda para a manutenção da família (BRUMER, 1996).

Contudo, enfatiza-se que a divisão sexual das atividades desenvolvidas por homens e mulheres no rural permanece. Quando as atividades produtivas direcionam-se ao autoconsumo e isentas de remuneração, são as mulheres que, majoritariamente, as desenvolvem. Porém, ao se referir às atividades remuneradas, a grande maioria é desempenhada por homens. Exemplo disso é que atividades ditas masculinas, como lavoura e pecuária, quando desenvolvidas por mulheres, ganham caráter de complementariedade à subsistência da família, de extensão das atividades praticadas por mulheres no ambiente doméstico (MELO; DI SABBATO, 2006).

A inserção da população participante do Brasil sem Miséria em Encruzilhada do Sul nas atividades de bovinocultura e ovinocultura representa a maioria das atividades produtivas nas propriedades, induzindo à reflexão de que, se estas são para o autoconsumo, consequentemente, as possibilidades de serem desenvolvidas por mulheres são significativas. A presença das atividades se reafirma ao se verificar as aquisições por intervenção do programa no intuito de contribuir para o 
Inclusão produtiva, pecuária familiar e situação das mulheres rurais do Programa Brasil Sem Miséria em um município do RS - contexto de uma realidade pouco conhecida

aperfeiçoamento produtivo, assim como inserção de alternativas produtivas nos estabelecimentos enquadrados na ação. A representatividade das aquisições envolvendo bovinos e outros animais, ou outros materiais, concentrou-se em $48,89 \%$ dos casos e, a mesma situação em relação aos ovinos, 21,11\%.

Dentre as aquisições que contemplaram bovinos e ovinos, $23,33 \%$ ocorrem em estabelecimentos que antes do programa não desenvolviam estas atividades. Cabe ressaltar que as aquisições buscaram atender às necessidades das famílias, em que cada participante teve seus projetos direcionados a sua realidade. Dessa forma, houve ampla diversidade na combinação de itens adquiridos, dentre os quais, além de bovinos e ovinos, contemplou-se aves, suínos, caprinos e materiais para a construção de estruturas produtivas, como galinheiros e potreiros.

A pluralidade das situações familiares reflete as diferentes combinações de produção retomando a dimensão da autonomia dos pecuaristas familiares. Essas multiplicidades exemplificam as distintas estratégias adotadas pelos atores no sentido de suprirem suas necessidades, que se sustentam no domínio produtivo e buscam autonomia familiar no que tange aos mercados (NESKE, 2009).

Algumas particularidades dos pecuaristas familiares são encontradas em estudos que buscam definir tipos familiares, como pecuaristas familiares pouco integrados com o mercado e dependentes de outras atividades para a reprodução familiar e pecuaristas com baixa integração de mercado e dependência de transferências sociais para a reprodução familiar (NESKE, 2009). A pluriatividade e o recebimento de benefícios sociais para a subsistência da família são características que se repetem na realidade analisada e no estudo do autor, aproximando este público com as especificidades que contribuem para a definição da categoria social dos pecuaristas familiares.

As formas de comercialização da produção, especialmente dos bovinos de corte, também são particularidades das dinâmicas familiares. A não comercialização dos participantes do Programa é de $37,36 \%$ da totalidade e 35,16\% comercializam diretamente com a vizinhança. Dentre as demais formas de comercialização, percebe-se que grande parte envolve a vizinhança e outros compradores, como intermediários, frigorífico, empresas, vendas em domicílio e barraca, aumentando para $46,16 \%$ a representatividade de meios de comercialização que abrangem a vizinhança. E 13,2\% não vendem para a vizinhança, apenas para os demais canais de comercialização mencionados.

No tocante à comercialização, Sandrini (2005) estudou as formas de inserção dos pecuaristas familiares na cadeia produtiva da carne, considerando, especialmente, as decisões econômicas acerca da comercialização de bovinos de corte. Dentre as variáveis que explicam a reprodução das unidades familiares, encontram-se as endógenas (relações de parentesco, herança, trabalho familiar) e exógenas à propriedade familiar. Esta última abrange as relações da família com os mercados e instituições sociais, ou seja, a comercialização é discutida nesse espaço múltiplo de relações externas à propriedade que determinam as estratégias de reprodução familiar.

O espaço da comercialização não é dominado por mulheres, principalmente em função de sua reduzida autonomia econômica e dificuldades de gestão dos recursos advindos de seu trabalho (BUTTO, 2006). Isso mostra que a atuação da mulher se faz no espaço endógeno, onde o trabalho feminino é percebido como 
"extensão do papel da mulher no âmbito da família" (MELO; DI SABBATO, 2006, p. 85). Dessa forma, as variáveis endógenas contemplam, em grandes parcelas, as mulheres, enquanto o caráter exógeno à propriedade, como a comercialização, fica sob responsabilidade dos homens.

A autonomia do pecuarista, em se tratando de subsistência, define as decisões comerciais referentes aos bovinos, podendo esta atividade representar pequena parcela da renda, já que a produção pecuária é combinada com outras fontes agrícolas e não agrícolas (COTRIM, 2003). Em alguns casos, a comercialização é realizada apenas em momentos de necessidades financeiras, revelando que a lógica familiar preocupa-se com o sustento dos membros e não com a lucratividade. Assim, os bovinos de corte passam a ser percebidos como uma espécie de poupança dos pecuaristas familiares (SANDRINI, 2005).

A área fundiária é um dos elementos que compunham as especificações apontadas por Ribeiro (2009) na caracterização dos pecuaristas familiares, pois estariam enquadrados nesta categoria social aqueles pecuaristas como o máximo de 300 hectares. Os dados analisados atestam essa particularidade, pois a maior área, dentre os participantes do Brasil Sem Miséria, é de 148 hectares e a média corresponde a 15,04 hectares. Para se ter uma ideia da amplitude das áreas, 0 mínimo encontrado foi de 0,1 hectares até 148 hectares.

Com base nas informações apresentadas, é possível perceber as semelhanças das dinâmicas produtivas familiares com a pecuária familiar. Isso demonstra a diversidade de vivências encontradas no rural e comprova a multiplicidade da pecuária no Rio Grande do Sul, especialmente em se tratando da pecuária familiar. A pobreza também faz parte das realidades que permeiam a pecuária, contestando o culturalmente atribuído como representação dominante da pecuária na Metade Sul do Estado.

\section{Considerações finais}

Por meio do Brasil Sem Miséria, a pecuária familiar mostrou-se como uma oportunidade de inserção produtiva das famílias participantes da ação, já que, em vários casos, a ovinocultura e bovinocultura foram inseridas a partir dos benefícios concedidos pelo programa. Ademais, as informações analisadas permitiram averiguar que grande parte dos grupos familiares classificados como extremamente pobres desenvolvem a pecuária familiar como atividade produtiva.

Essa constatação remete às diferentes realidades inseridas na pecuária no Rio Grande do Sul, oportunizando um olhar distinto sobre a realidade das construções sociais dominantes acerca da pecuária no Estado. Em conformidade com as múltiplas faces da pecuária evidenciadas, está o reconhecimento da participação feminina nessas dinâmicas, dado que ela é predominantemente considerada como atividade masculina.

É possível que esse reconhecimento seja dificultado, ou até mesmo oculto, nas práticas sociais e intrafamiliares. Entretanto é evidente que as mulheres exercem atividades ditas masculinas, como o manejo e sanidade dos animais, transcendendo as tarefas domésticas (LITRE, 2010). A divisão sexual do trabalho nas unidades rurais carrega consigo a tradicional permanência do entendimento de que há "coisas de homem e coisas de mulher", sendo estas determinadas pela força 
Inclusão produtiva, pecuária familiar e situação das mulheres rurais do Programa Brasil Sem Miséria em um município do RS - contexto de uma realidade pouco conhecida

dispendida para realizar certas atividades, assim como o local em que são exercidos os distintos ofícios: "o campo é o espaço do homem, logo, ele é o responsável pela pecuária”, é uma das evidências observadas por Lunardi (2012, p. 89).

Contudo, a identificação dos grupos familiares potenciais para a participação no Brasil Sem Miséria foi a partir do Cadúnico e inserção no Bolsa Família, em que os titulares são predominantemente mulheres. Posto que a maioria dos estabelecimentos insere-se nas especificidades da pecuária familiar, a identificação do público potencial a participar do programa seria, em tese, por meio dos homens. Assim, questiona-se até que ponto a pecuária é atividade masculina? Ou melhor, seria a pobreza um "parâmetro" para caracterizar atividades rurais, inclusive a pecuária, como femininas?

A pobreza pode ser vista como construção social e, frequentemente, está associada à condição/situação feminina, materializando-se de diversas formas. A pecuária no Rio Grande do Sul não é observada a partir de olhares múltiplos, onde a pobreza e as mulheres estejam analisadas em sua transversalidade. Essas reflexões remetem às interrogações anteriores e reiteram as assimetrias nas relações de gênero imersas no rural.

\section{REFERÊNCIAS}

ALMEIDA, Jalcione. et al. Pesquisa interdisciplinar na pós-graduação: (des)caminhos de uma experiência em andamento. Revista Brasileira de Pós-Gradução, v. 1, n. 2, p. 116-40, setembro, 2004.

BECK, Fabio de Lima et al. Construção de uma problemática interdisciplinar de pesquisa: trajetórias e reflexões. In: PHILIPPI, A. Jr. e SILVA NETO, A. J.

Interdisciplinaridade em ciência, tecnologia e inovação. Barueri: Editora Manole, 2011.

BECKER, Gabriela Liedtke. Representações de gênero no tradicionalismo gaúcho. In: IV Diálogos do PET, 2010, Curitiba. Anais... Curitiba: Universidade Federal do Paraná, 2010.

BRASIL. Ministério do Desenvolvimento Social e Combate à Fome. Plano Brasil Sem Miséria no seu município: o que são, para que servem e como acessar os principais programas e serviços do Brasil Sem Miséria no seu município. Brasília: 2013.

BRASIL. Ministério do Desenvolvimento Social e Combate à Fome. O Brasil Sem Miséria no seu município: Encruzilhada do Sul. Brasília: 2015.

BRUMER, Anita. O sexo da ocupação: considerações teóricas sobre a inserção da mão de obra feminina na força de trabalho. Revista Brasileira de Ciências Sociais, São Paulo, v. 3, n. 8, p. 20-38, out. 1988.

. Mulher e Desenvolvimento Rural. In: PRESVELOU, Clio; ALMEIDA, Francesca Rodrigues; ALMEIDA, Joaquim Anécio. Mulher, família e desenvolvimento rural. 
Santa Maria: UFSM, 1996.

. Gênero e agricultura: a situação da mulher na agricultura do Rio Grande do Sul. Revista Estudos Feministas, v.12, n. 1. p. 205-227, Jan./Abril, 2004.

BUTTO, Andrea. Políticas para as mulheres trabalhadoras rurais: um compromisso de todos os dias. In: BRASIL. Ministério do desenvolvimento Agrário. Gênero, agricultura familiar e reforma agrária no Mercosul. Brasília: Ministério do Desenvolvimento Agrário, 2006.

CAMPOS, Christiane Senhorinha Soares. A face feminina da pobreza em meio à riqueza do agronegócio. Buenos Aires: CLACSO, 2011.

CARGNIN, Antonio Paulo. A oposição entre o norte e o sul: políticas para o desenvolvimento da Metade Sul do Rio Grande do Sul. In: CARGNIN, Antonio Paulo. Políticas de Desenvolvimento Regional no Rio Grande do Sul: Vestígios, Marcas e Repercussões Territoriais. Brasília: Ministério da Integração Nacional, 2014.

COTRIM, Marcelo Souza. "Pecuária familiar" na região da "Serra do Sudeste" do Rio Grande do Sul: um estudo sobre a origem e a situação socioagroeconômica do pecuarista familiar no município de Canguçu/RS. Dissertação - Programa de Pós-Graduação em Desenvolvimento Rural, Universidade Federal do Rio Grande do Sul, Porto Alegre, 2003.

EMATER RS - Escritório Municipal de Encruzilhada do Sul. Diagnóstico da unidade produtiva familiar 2012/2013. EMATER RS: Encruzilhada do Sul, 2015.

IBGE. Instituto Brasileiro de Geografia e Estatística. Sistema Nacional de Informação de Gênero: uma análise dos resultados do censo demográfico - 2010. Disponível em: <http://www.cidades.ibge.gov.br/xtras/temas.php?lang=\&codmun=430690\&idtema $=132 \&$ search=rio-grande-do-sul|encruzilhada-do-sul|sistema-nacional-de-informacaode-genero-uma-analise-dos-resultados-do-censo-demografico-2010> Acesso em: 28 maio 2015.

IBGE. Instituto Brasileiro de Geografia e Estatística. Disponível em: <http://www.cidades.ibge.gov.br/xtras/perfil.php?lang=\&codmun=430690\&search= rio-grande-do-sul|encruzilhada-do-sul|infograficos:-informacoes-completas_>. Acesso em: 23 maio 2015.

LITRE, Gabriela. Os gaúchos e a globalização: vulnerabilidade e adaptação da pecuária familiar no Pampa do Uruguai, Argentina e Brasil. 2010. Tese (Doutorado em Desenvolvimento Sustentável) - Centro de Desenvolvimento Sustentável, Universidade Federal de Brasília, Brasília, 2010.

LOMBARDI, Maria Rosa. A ocupação no setor agropecuário no período de 1993-2006 e o trabalho das mulheres. In: DI SABBATO, Alberto. Estatísticas rurais e a economia feminista: um olhar sobre o trabalho das mulheres. Brasília: MDA, 2009. 
Inclusão produtiva, pecuária familiar e situação das mulheres rurais do Programa Brasil Sem Miséria em um município do RS - contexto de uma realidade pouco conhecida

LOURO, Guacira Lopes. Nas redes do conceito de gênero. In: LOPES, Marta Júlia Marques; MEYER, Dagmar Estermann; WALDOW, Vera Regina. (Orgs.) Gênero e Saúde. Porto Alegre: Artes Médicas, 1996.

LUNARDI, Raquel. Mudanças nas relações de trabalho e gênero no turismo rural. Tese (Doutorado em Desenvolvimento Rural) - Programa de Pós Graduação em Desenvolvimento Rural, Universidade Federal do Rio Grande do Sul, Porto Alegre, 2012.

MARTINEZ, RossanaVitelli. Capital social, participação e cidadania no meio rural: uma perspectiva de gênero. Tese (Doutorado em Sociologia) - Programa de Pós-Graduação em Sociologia, Universidade Federal do Rio Grande do Sul, Porto Alegre, 2010.

MATTE, Alessandra; WAQUIL, Paulo Dabdab; NESKE, Márcio Zamboni. Dinâmicas socioeconômicas e produtivas das microrregiões Campanha Meridional e Serra do Sudeste - RS. In: $7^{\circ}$ Encontro da Economia Gaúcha, 2014, Porto Alegre. Anais...Porto Alegre: Fee, 2014. Disponível em:

<http://www.fee.rs.gov.br/wp-content/uploads/2014/05/201405267eeg-mesa21-dina micassocioeconomicasprodutivasmicroregioescampanhameridional.pdf $>$. Acesso em: 22 maio 2015.

MELO, Hildete Pereira; DI SABBATO, Alberto. Mulheres rurais: invisíveis e mal remuneradas. In: BRASIL. Ministério do desenvolvimento Agrário. Gênero, agricultura familiar e reforma agrária no Mercosul. Brasília: Ministério do Desenvolvimento Agrário, 2006.

NARCISO, Vanda; HENRIQUES, Pedro Damião de Souza. O papel das mulheres no Desenvolvimento Rural: uma leitura para Timor-Leste. Universidade de Évora. Portugal, 2008. Disponível em: <http://www.cefage.uevora.pt/en/content/download/1257/16439/version/1/file/2008 _04.pdf.>Acesso em: 25 maio 2015.

NESKE, Márcio Zamboni. Estilos de agricultura e dinâmicas locais de desenvolvimento rural: o caso da Pecuária Familiar no Território Alto Camaquã do Rio Grande do Sul. Dissertação (Mestrado em Desenvolvimento Rural)- Programa de Pós-graduação em Desenvolvimento Rural, Universidade Federal do Rio Grande do Sul, Porto Alegre, 2009.

PORTO, Rafael Gasta. Caracterização da pecuária familiar na região da Campanha Meridional: estudo de caso no município de Bagé-RS. Dissertação (Mestrado em Ciências - Desenvolvimento Rural Sustentável) - Programa de Pós-Graduação em Sistemas de Produção Agrícola Familiar, Universidade Federal de Pelotas, Pelotas, 2008.

RAUBER, Cassiane da Costa. Masculinização da população rural no Rio Grande do 
Sul: análise a partir dos sistemas agrários. Dissertação (Mestrado em Extensão Rural) - Programa de Pós-graduação em Extensão Rural, Universidade Federal de Santa Maria, Santa Maria, 2010.

RIBEIRO, Claudio Marques. Estudo do modo de vida dos pecuaristas familiares da Região da Campanha do Rio Grande do Sul. Tese (Doutorado em Desenvolvimento Rural) - Programa de Pós-graduação em Desenvolvimento Rural, Universidade Federal do Rio Grande do Sul, Porto Alegre, 2009.

SANDRINI, Gisléia Benini Duarte. Processo de inserção dos pecuaristas familiares do Rio Grande do Sul na cadeia produtiva da carne. Dissertação (Mestrado em Desenvolvimento Rural)- Programa de Pós-graduação em Desenvolvimento Rural, Universidade Federal do Rio Grande do Sul, Porto Alegre, 2005.

SCOTT, Joan Wallach. "Gênero: uma categoria útil de análise histórica”. Educação \& Realidade, Porto Alegre, v. 20, n. 2, p. 71-99, jul./dez. 1995.

SEN, Amartya Kumar. Desenvolvimento como liberdade. 7. reimpressão. São Paulo: Companhia das Letras, 2000.

Marta Julia Marques Lopes. Doutora em Sociologia. Professora Titular da Universidade Federal do Rio Grande do Sul. E-mail: marta@enf.ufrgs.br.

Tatielle Belem Langbecker. Tecnóloga em Agronegócio. Mestre em Desenvolvimento Rural pela Universidade Federal do Rio Grande do Sul. Doutoranda em Extensão Rural pela Universidade Federal de Santa Maria. E-mail: tatielle.belem@gmail.com 